\title{
An evaluation of tick and Lyme disease information on health unit websites in Ontario
}

\author{
Kaitlyn Irving* and Lindsay Galway \\ Department of Health Sciences, Lakehead University, Thunder Bay, ON, Canada
}

\begin{abstract}
Climate change has allowed for the expansion and intensification of blacklegged ticks; the vector of Lyme disease. Projections estimate that by the year 2049 all health units in Ontario will have suitable environmental conditions for the establishment of this vector. A review of website content from health units in Ontario was performed to assess the quality of tick and Lyme disease information provided to the public and health care providers. Websites were evaluated based on criteria such as the provision of Lyme disease information (i.e., transmission, symptoms, treatment, etc.), the inclusion of misleading or incorrect information, and visuals provided. The quality of textual and visual information varied substantially across the 35 health units analyzed. Eleven health units were found to provide misleading or incorrect information. Disparities were found between areas with current Lyme disease risk and those without. The majority of health units did not include satisfactory visual content pertaining to ticks. Given the expected expansion and intensification of blacklegged tick populations across the province, all health units must ensure the information communicated to the public about ticks and Lyme disease is of high-quality and consistent. We conclude with specific recommendations to improve the textual and visual content of websites.
\end{abstract}

Key words: blacklegged ticks, Lyme disease, websites, Ontario, knowledge translation.

Over the last decade, Canada has experienced a dramatic intensification and expansion in blacklegged tick (Ixodes scapularis) populations. With this vector comes the subsequent risk for Lyme disease. Between 2009 and 2013, blacklegged tick populations quintupled across Canada with almost $50 \%$ of this increase occurring in the province of Ontario (Berry et al., 2014). Most recent data have illustrated the incidence rate of Lyme disease in 2017 was three times higher than the five-year average between 2012 and 2016 (Nelder et al., 2018). Annually, Public Health Ontario (PHO) produces an Ontario Lyme Disease Map: Estimated Risk Areas (PHO, 2018). Estimated risk areas are defined as "locations where blacklegged ticks have been identified or are known to occur and where humans have the potential to come into contact with infected ticks" (Odgen et al., 2014; PHO, 2018). It is calculated "as a $20 \mathrm{~km}$ radius from the centre of a location where blacklegged ticks were found through drag sampling" (PHO, 2018). From 2016 to 2018, these risk maps illustrated an expansion within eastern health units and the emergence of new risk areas such as in Hamilton and in the Simcoe-Muskoka District (Appendix A) (PHO, 2018). Although the risk is low, PHO states that members of the public can still encounter infective ticks anywhere in the province due to transportation on migratory birds (PHO, 2018).

*Corresponding author: Kaitlyn Irving (email: kirving@lakeheadu.ca)
Lyme disease intensification is largely attributed to climate change. Since 1990, the Ministry of the Environment, Conservation, and Parks calculated that temperatures in Ontario have increased at a rate of $1.3^{\circ} \mathrm{C}$ per 100 years (Government of Ontario, 2018). Because of the rapid acceleration of warming, annual temperatures are expected to increase to $3.6^{\circ} \mathrm{C}$ by the year 2050 (Government of Ontario, 2018). Warmer temperatures allow for faster maturation of the Lyme disease bacteria within ticks and make other areas of the province ideal for habitation (Ebi et al., 2016; Estrada-Peña et al., 2012). Research has shown the geographic range of ticks is highly likely to expand across the province. Ogden et al. (2008) used various algorithms to predict blacklegged tick populations throughout Ontario under future projected climate scenarios (Ogden et al., 2008). Ogden et al. (2008) determined risk areas were based on temperature suitability, ticks immigrating on birds, and percentage of forest habitat. Conditions in 2008 yielded, " 219 census subdivisions (CSD) [that] were classified as 'high risk', 1875 as 'moderate risk' and 1514 as 'low risk' " (Ogden et al., 2008). Ogden et al. (2008) estimated that by the year 2049, high-risk areas will increase to 699 and moderate-risk areas will increase to 4793 CSD. By 2079, high-risk areas will increase to 1065, and moderate-risk CSD will increase to 6640 (Ogden et al., 2008). Consequently, cases of Lyme disease are expected to increase across all regions of Ontario in the future. These data highlight an emerging public health issue of great concern-one that Ontarians and public health units (PHUs) must prepare for. 
Websites are an important knowledge translation tool for PHUs as they are easily accessible to both the public and health care providers. The Internet has become a staple in Canadian life as $89 \%$ of the nation report daily usage (Statista, 2018). Specifically, $84.1 \%$ of Ontario citizens reported access to the Internet at home in 2012 (Statistics Canada, 2018). The use of websites as a point of access for acquiring information has become integrated into everyday life. It is important that information provided on PHU websites is clear, easy to understand, and accurate. With regards to ticks and Lyme disease information, the provision of high-quality, accurate, and consistent information on PHU websites can improve risk communication, enhance general knowledge, reduce misconceptions and fears, encourage preventative behaviours, and promote timely and accurate diagnoses and treatment when needed.

The overall purpose of this paper is to promote the provision of consistent and high-quality information by all PHUs in Ontario to improve overall knowledge of ticks and Lyme disease among Ontarians. The specific objectives of this paper are: $(i)$ to evaluate textual and visual information on ticks and Lyme disease provided by PHU websites, (ii) to compare the information provided by those PHUs with and without current Lyme disease activity, (iii) to address inconsistences pertaining to misinformation in website content, and (iv) to provide recommendations for improvement based on these evaluations.

\section{Methods}

An analysis of the websites created by the 35 PHUs in Ontario was assessed for information for the public as well as health professionals on ticks and Lyme disease. Data were collected between 4 and 16 June 2018. The assessment was twofold. The first step was to visually determine if PHUs contained Lyme disease risk areas as per the PHO document entitled Ontario Lyme Disease Map 2018: Estimated Risk Areas (Appendix A) (PHO, 2018). PHUs were categorized based on those without any estimated activity of Lyme disease as per the PHO risk map $(n=9)$ and those that contained activity $(n=26)$ (Appendix A and Table 1). This was done to enable comparison of website content between PHUs with and without Lyme disease activity.

Next, the textual and visual information on websites directed to the public and health care providers were analyzed for all PHUs. A review was performed on websites designated for "ticks" and (or) "Lyme disease." The content was assessed based on the following criteria: cause and transmission, signs and symptoms, treatment, prevention, information on tick removal, misleading or incorrect information, and links to climate change. Content was deemed satisfactory if it aligned with tick and Lyme disease information published on the Public Health Agency of Canada (PHAC), PHO, and the Ontario Ministry of Health and Long-Term Care (MOHLTC) websites. Content criteria that were deemed satisfactory were recorded into an Excel spreadsheet. If criteria were satisfactory, it was recorded as "Y" in the spreadsheet and "N" if it did not. Data were then analyzed using basic descriptive statistics, frequencies, and percentages to summarize findings (Table 2). A similar process was used to assess visual content. Specifically, visual content was assessed based on the following criteria: the provision of a hyperlink to PHO's Lyme disease risk map, inclusion of blacklegged tick images (male and female), if pictures were labelled, provision of the blacklegged tick life cycle, inclusion of other tick species, and the provision or link to an informational video. If criteria were

Table 1. Ontario PHUs with Lyme disease risk areas as per PHO

\begin{tabular}{|l|l|c|}
\hline Risk & PHU & Total \\
\hline No risk areas present & $\begin{array}{l}\text { Algoma District, Grey Bruce, North Bay Parry Sound District, Perth District, Porcupine, } \\
\text { Southwestern, Sudbury, Thunder Bay District, and Timiskaming }\end{array}$ & 9 \\
\hline Risk areas present & $\begin{array}{l}\text { Brant County, Chatham-Kent, Durham Regional, Eastern Ontario, Haldimand-Norfolk, Haliburton } \\
\text { Kawartha Pine Ridge District, Halton Regional, Hamilton, Hastings Prince Edward Counties, }\end{array}$ & 26 \\
& $\begin{array}{l}\text { Huron County, Kingston Frontenac Lennox and Addington, Lambton, Leeds Grenville and Lanark } \\
\text { District, Middlesex-London, Niagara Regional Area, Northwestern, Ottawa, Peel Regional, } \\
\text { Peterborough County-City, Renfrew County and Districts, Simcoe Muskoka District, Toronto, } \\
\text { Waterloo, Wellington-Dufferin-Guelph, Windsor-Essex County, and York Regional. }\end{array}$ & \\
\hline
\end{tabular}

Table 2. Summary of textual website content provided on PHU websites in Ontario

\begin{tabular}{|l|c|c|c|}
\hline $\begin{array}{l}\text { Content evaluation } \\
\text { criteria }\end{array}$ & $\begin{array}{c}\text { PHUs with } \\
\text { satisfactory content, } \\
\text { no. }(\mathbf{\%}) ;(\boldsymbol{n}=\mathbf{3 5})\end{array}$ & $\begin{array}{c}\text { PHUs with Lyme disease risk } \\
\text { areas with satisfactory content, } \\
\text { no. }(\mathbf{\%}) ;(\boldsymbol{n}=\mathbf{2 6})\end{array}$ & $\begin{array}{c}\text { PHUs without Lyme disease } \\
\text { risk areas with satisfactory } \\
\text { content, no. }(\mathbf{\%}) ;(\boldsymbol{n}=\mathbf{9})\end{array}$ \\
\hline Cause and transmission & $34(97.1)$ & $26(100)$ & $8(88.9)$ \\
\hline Signs and symptoms & $27(77.1)$ & $23(88.5)$ & $4(44.4)$ \\
\hline Treatment & $21(60)$ & $17(65.4)$ & $4(44.4)$ \\
\hline Prevention & $33(94.3)$ & $25(96.2)$ & $8(88.9)$ \\
\hline Information on tick removal & $31(88.6)$ & $24(92.3)$ & $7(77.8)$ \\
\hline $\begin{array}{l}\text { Misleading or incorrect } \\
\text { information }\end{array}$ & $11(31.4)$ & $7(26.9)$ & $4(44.4)$ \\
\hline Link to climate change & $4(11.4)$ & $2(7.7)$ & $2(22.2)$ \\
\hline
\end{tabular}


fulfilled, it was recorded as " $Y$ " in an Excel spreadsheet and " $N$ " if it did not. The websites that were coded as "Y" for each criterion were calculated using frequencies and percentages and summarized in Table 3. Responses were summarized and a final score was calculated. It should be noted that information on social media platforms, council meetings, secondary sources (i.e. PowerPoint presentations, digital pamphlets, digital posters, etc.), and news releases were not included in the analysis.

It is important to address the limitations of this study when interpreting findings. We acknowledge that website information is constantly changing and PHUs may have updated their website since data were collected June 2018. Also, social media platforms and other secondary sources, like PowerPoint presentations, were excluded from the study. As a result, we may have missed more detailed information that could have allowed a PHU to meet more criteria.

\section{Results}

\section{Textual content evaluation}

A summary of the evaluation of the textual content across all 35 PHU websites is provided in Table 2. The majority of PHUs provided Lyme disease information on cause and transmission (97.1\%), prevention (94.3\%), and information on tick removal (88.6\%). In terms of signs and symptoms, $77.1 \%$ of PHUs provided this information. Fewer PHUs provided information on treatment $(60 \%)$ or made the link to climate change as contributing to the expansion of blacklegged ticks (11.4\%). In total, 11 PHUs provided misleading or incorrect information, which will be addressed in the discussion section.

Differences were found regarding important Lyme disease information across PHUs with estimated activity of Lyme disease as per the PHO risk map and those without (Table 2). Only $44.4 \%$ of PHUs without estimated activity provided information on signs and symptoms. This is compared with $88.5 \%$ for areas with risk. Regarding Lyme disease treatment, $44.4 \%$ of PHUs without estimated activity provided this information compared with $65.4 \%$ of PHUs with risk. In total, $44.4 \%$ of PHUs without estimated activity of Lyme disease provided misleading or incorrect information compared with $26.9 \%$ of PHUs with risk.

\section{Visual content evaluation}

A summary of the evaluation of the visual content across all 35 PHU websites is provided in Table 3. Overall, 27 PHUs provided images of ticks on their websites. Of those that did, $57.1 \%$ of these PHUs did not label the image of a tick, $71.4 \%$ did not provide an image of a male blacklegged tick, $80 \%$ did not show the blacklegged tick lifecycle, and $71.4 \%$ did not provide images of other species.

Differences were noted with the use of visuals for those PHUs located within estimated Lyme disease risk areas (Table 3). Only $53.9 \%$ of these PHUs provided, or made the link to, PHO's Ontario Lyme Disease Map 2018: Estimated Risk Areas. Overall, six of the 26 PHUs with estimated risk areas did not provide images of what the vector looked like. Of those that did: 65\% did not show an image of a male blacklegged tick, $35 \%$ did not show images of blacklegged ticks at different life stages, and 65\% did not provide other species for comparison. Nonaffected PHUs showed comparable rates.

\section{Discussion}

\section{Textual content}

Eleven PHUs provided misleading or incorrect information regarding symptoms, transmission, and risk areas. Of those PHUs, 73\% listed the bulls-eye rash (i.e., Erythema Migrans) as a symptom without explicitly stating that it does not always occur to indicate a positive infection (Centres for Disease Control and Prevention (CDC), n.d.). It is also important to note rashes associated with Lyme disease do not always look like a bulls-eye (CDC, n.d.). This information can imply that the

Table 3. Summary of visual website content provided on PHU websites in Ontario

\begin{tabular}{|l|c|c|c|}
\hline $\begin{array}{l}\text { Content evaluation } \\
\text { criteria }\end{array}$ & $\begin{array}{c}\text { PHUs with } \\
\text { satisfactory content, } \\
\text { no. }(\mathbf{\%}) ;(\boldsymbol{n}=\mathbf{3 5})\end{array}$ & $\begin{array}{c}\text { PHUs with Lyme disease risk } \\
\text { areas with satisfactory content, } \\
\mathbf{n o .}(\mathbf{\%}) ;(\boldsymbol{n}=\mathbf{2 6})\end{array}$ & $\begin{array}{c}\text { PHUs without Lyme } \\
\text { disease risk areas with } \\
\text { satisfactory content, no. } \\
\mathbf{( \% )}(\boldsymbol{n}=\mathbf{9})\end{array}$ \\
\hline $\begin{array}{l}\text { Provision or link to PHO } \\
\text { risk map }\end{array}$ & $18(51.4)$ & $14(53.9)$ & $4(44.4)$ \\
\hline $\begin{array}{l}\text { Provision or link to an } \\
\text { informational video }\end{array}$ & $10(28.6)$ & $8(30.8)$ & $2(22.2)$ \\
\hline Blacklegged tick shown & $27(77.1)$ & $20(76.9)^{\mathrm{a}}$ & $7(77.8)^{\mathrm{b}}$ \\
\hline Tick is labelled & $15(42.9)$ & $12(60)$ & $3(42.9)$ \\
\hline $\begin{array}{l}\text { Female blacklegged tick } \\
\text { shown }\end{array}$ & $27(77.1)$ & $20(100)$ & $7(100)$ \\
\hline Male blacklegged tick shown & $10(28.6)$ & $7(35)$ & $3(42.9)$ \\
\hline $\begin{array}{l}\text { Blacklegged tick life cycle } \\
\text { shown }\end{array}$ & $7(20)$ & $6(30)$ & $1(14.3)$ \\
\hline Other species shown & $10(28.6)$ & $7(35)$ & $3(42.9)$ \\
\hline
\end{tabular}

aSubsequent columns divided by this number.

${ }^{b}$ Subsequent columns divided by this number. 
rash must appear to have the disease-a common misunderstanding among the public. This could prevent the public from seeking medical attention if they have been bitten but do not develop a rash. A PHU that is currently not affected by Lyme disease also stated that ticks must be removed within 36 hours to reduce transmission, as per the CDC, which is an Americanbased agency (CDC, n.d.). However, the Infectious Disease Protocol (2015) by the MOHTLC outlines that ticks should be removed within 24 hours. Conflicting information can create confusion for readers and lead to mistrust from the public. This 12-hour difference in information could allow for the proliferation of the disease. One PHU stated that Lyme disease is more common in the United States than in Canada. Using dismissive language may cause Ontarians to not take preventative efforts seriously or assume that the overall risk is not of concern. Additionally, there were five PHUs that failed to include regions of the province that are known endemic areas for blacklegged ticks. For example, three PHUs stated that blacklegged ticks are found in southern Ontario when one northwestern PHU and many eastern PHUs are affected. Failure to adequately communicate risk areas may provide a false sense of security to the public when traveling to these areas. It can also contribute towards mistrust if a member of the public acquires a tick in an area that their PHU failed to disclose.

\section{Visual content}

In terms of visual content pertaining to ticks, our analyses indicated that most PHU websites did not include satisfactory visual content. Without showing an image of male blacklegged ticks, it implies that all ticks will look like the female. Showing this vector in various stages of life is vital as nymphs are not as easy to identify as their adult counterparts. This is because nymphs are tiny, and the trademark orange-brown body is not as pronounced at this stage. The public may not identify these nymphs as a vector for Lyme disease. In doing so, antibiotic intervention may be missed. Additionally, less than $30 \%$ of all websites included imagery of other tick species, like American dog ticks (Dermacentor variabilis), for the sake of comparison. If no other species are provided, it can contribute towards confusion and (or) unnecessary concern as the public will not be able to confidently determine which species causes Lyme disease. Providing this education can also help to reduce the number of other tick species submitted to passive surveillance programs, thus saving time and money.

Importantly, three PHUs were found to use incorrect or inappropriate images on their websites pertaining to Lyme disease information (Appendix B). Two images of American dog ticks were found on documents for health care professionals. Tick identification is a crucial part of treatment. The physician criteria for prophylactic treatment rely on the patient meeting strict clinical specifications (Government of Canada, 2018), one of which is the reliable identification of the tick being blacklegged (Government of Canada, 2018). With the wrong species on infographics, physicians may be confused as to which tick can transmit the bacteria with possible implications for antibiotic treatment. Another PHU had an image of what appeared to be a pill bug (Armadillidium vulgare) as the website banner for "Ticks and Lyme disease." This can infer to readers that ticks will have the same armored body as the pill bug. Misidentification can prevent the public from seeking out medical attention.

\section{Recommendations}

Drawing on our findings, we provide the following specific recommendations to promote the provision of consistent and high-quality information pertaining to ticks and Lyme disease by all PHUs in Ontario on their websites:

(1) Improve general tick and Lyme disease content

(2) Improve and enhance the use of visuals

(3) Utilize videos

(4) Include first-hand accounts of Lyme disease

(5) Consider providing geospatial tools for visualizing risk areas

(6) Make the link between Lyme disease and climate change

Information on Lyme disease provided on public health websites should include cause and transmission, signs and symptoms, treatment, prevention, and information on tick removal. The PHAC, PHO, and the MOHTLC should be used as primary sources for Lyme disease and general tick information to ensure accuracy and improve consistency. This information will act as a point of reference for the public and health care providers, more effectively communicating risk, improving general understanding of the disease, and helping citizens decide when they should seek medical attention. Numerous studies have shown health education can help to improve overall knowledge of health risks and encourage preventative behaviours. For example, Mohammadi et al. (2012) and Wilches et al. (2011) identified that educational programs delivered to students and adults increased knowledge of tuberculosis as well as encouraged preventative behaviours to reduce the risk of tuberculosis. Furthermore, the provision of general information on ticks and Lyme disease can help to reduce fear among citizens by providing a complete and evidence-based picture of the disease and disease risk. This can ultimately deter viewers from consulting "junk science" for answers. We cannot assume that the public will do supplementary research if the information is not all presented on PHU websites.

Improvement and enhancement of visual information pertaining to ticks and Lyme disease on PHU websites is particularly important. Research has shown people can recall $65 \%$ of information three days later when it is paired with a visual (Marieb and Hoehn, 2007). It was also shown those who follow directions with text alongside visual aids perform 323\% better than those without visual aids (Levie and Lentz, 1982). Visuals clearly play a key role in effective knowledge translation. The provision of the PHO risk map is a crucial element of informed decision-making and to adequately communicate risk to the public in areas where they may live, work, or travel. Along with the map, it should be clearly stated and emphasized that there is a possibility of encountering an infective blacklegged tick anywhere in Ontario (PHO, 2018). It is also necessary that all PHUs provide accurate images of blacklegged ticks. Showing images of both male and female blacklegged ticks at various stages of life and other species for comparison will aid the public in confidently identifying the vector of concern. In doing so, the public can determine whether medical intervention is appropriate.

Websites that embed videos on ticks and (or) Lyme disease (i.e., YouTube) provide an excellent alternative for those who are illiterate, children, and auditory and visual learners. Besides this, several decades of research have highlighted the numerous 
benefits of educational videos on memory retention and mastery (The University of Queensland, n.d.). Early studies from psychology professors Shepard and Cooper (1982) highlighted the relationship between visual cues on memory retention and its effect on the viewers' ability to remember new information. A series of experiments by Mayer and Gallini (1990) found participants that followed instructions using an illustrated video improved performance on the ability to remember conceptual information. If viewers can interact with the web-based media it can assist with mastery of content and promote active viewing (Galbraith, 2004). Currently, only 10 PHUs provide a video link of some kind. We recommend that PHUs create a personalized video or utilize videos from reputable sources such as Dr. Curtis Russell, senior program specialist at PHO. Some of Dr. Russell's videos include: "The Bug Guy - Ticks and Lyme disease," "Don't Get Ticked Off, Get the Tick Off," and "Tick Talk with the Bug Doc."

One PHU provided a unique insight into life with Lyme disease by including stories from their citizens that contracted the disease. Survivor stories are important because they provide a message of hope and encourage others to seek medical attention if a reader shares a similar experience. A study by McQueen et al. (2011) recruited women over the age of 40 to either watch a content-based video on breast cancer or another video as told by breast cancer survivors. Those who were exposed to the information video with first-hand accounts "identified more with the message source, and were more engaged with the videos...narratives, negative affect, identification, identification, and engagement influenced counterarguing, which in turn influenced perceived barriers and cancer fatalism" (McQueen et al., 2011, p. 674). These women were then more likely to speak with their family members about breast cancer that contributed to message recall (McQueen et al., 2011). Survivor stories from citizens can drive home the message that preventive efforts are important and Lyme disease should be taken seriously within the province.

In the digital age, Canadians are one of the highest mobile usage consumers in the world with over 30 million mobile subscribers in 2016 (Statista, 2017). Nationally, 29\% of online traffic in January 2017 was from the use of mobile phones (Statista, 2017). Knowing this, PHUs are encouraged to take advantage of this form of mass communication by creating a mobile application (app) pertaining to ticks and Lyme disease in their area based on active and (or) passive surveillance. Allowing users to access geospatial tools for visualizing risk would be a great way to foster informed decision-making. This information can be quickly accessed at any point of the day. Citizens can visualize the various degrees of tick activity where they live, work, or travel and decide if they want to put themselves at risk. The portability of mobile apps can also be beneficial to those who are hiking to know which areas of their trail have a higher risk of blacklegged ticks. Apps can also provide information on how best to protect oneself from tick bites or where you can submit a tick for identification. The field of mobile health is one that is still new and requires more research to support, or denounce, its effectiveness on knowledge translation (de la Vega and Miro, 2014; Hinze et al., 2017; Omboni et al., 2016; Free et al., 2013).

Lastly, we suggest that PHU websites make the links between ticks, Lyme disease, and climate change explicit for both the public and health care providers. Our findings illustrate that only four of the 35 PHUs explained the intensification and expansion of the Lyme disease vector within the province is linked to climate change. The MOHLTC has recently developed the "Ontario Climate Change and Health Vulnerability and Adaptation Assessment Guidelines" (Ebi et al., 2016). PHUs across the province are mandated to conduct vulnerability and adaptation assessments to fully comprehend the extent of climate change and to reduce health impacts, like Lyme disease, that will arise from global warming (Ebi et al., 2016). By including climate change information on the intensification of blacklegged ticks, PHUs can emphasize the emerging nature of this issue.

\section{Conclusion}

This paper presents an analysis of tick and Lyme disease information provided on PHU websites across the province of Ontario. We have identified a lack of consistency in terms of the quality and quantity of information that is provided via PHU websites. We have also identified notable differences in terms of the information provided between Lyme disease activity-positive and Lyme disease activity-negative PHUs. To promote the delivery of consistent and high-quality information about ticks and Lyme disease to all Ontarians, we encourage all PHUs to improve general tick and Lyme disease content, enhance the use of visuals, utilize more videos, include firsthand accounts of Lyme disease, consider providing geospatial tools for visualizing risk, and to make the links to climate change explicit on their websites.

As public health inspectors, our purpose is to protect citizens from various health hazards. One way we can do so is through education and knowledge translation. Consistent and effective information regarding blacklegged ticks and Lyme disease is crucial in preparing for the predicted intensification and expansion of tick populations and Lyme disease risk across Ontario. It will also be important for maintaining trust of the public. PHUs need to take a critical look at their websites to ensure that the textual and visual content will lead to a well-informed public.

\section{Acknowledgements}

The lead author would like to thank Peter Jekel and John Burnett for allowing her to be involved with the vectorborne disease team and sparking her interest in vectors. Their overwhelming support throughout this research was greatly appreciated. The lead author would also like to thank Dr. Jordan Tustin for giving her that needed push to produce published research.

\section{References}

Berry, P., Clarke, K., Fleury, M. D., and Parker, S. 2014. Human health. In F. J. Warren and D. S. Lemmen (eds.). Canada in a changing climate: Sector perspectives on impacts and adaptation (pp. 191-232). Ottawa, ON: Government of Canada.

CDC. n.d. Lyme disease: What you need to know. [Online] Available at: https://www.cdc.gov/lyme/resources/brochure/ lymediseasebrochure.pdf [Accessed on July 24, 2018]. 
de la Vega, R., and Miró, J. 2014. mHealth: A strategic field without a solid scientific soul: A systematic review of pain-related apps. PLoS One 9: 7. doi: 10.1371/journal.pone.0101312

Ebi, K., Anderson, V., Berry, P., Paterson, J., and Yusa, A. 2016. Ontario climate change and health vulnerability and adaptation assessment guidelines: Technical document. [Online] Available at: http:// www.health.gov.on.ca/en/common/ministry/publications/ reports/climate_change_toolkit/climate_change_toolkit.pdf [Accessed on July 24, 2018].

Estrada-Peña, A., Ayllón, N., and de la Fuente, J. 2012. Impact of climate trends on tick-borne pathogen transmission. Front Physiol. 3: 64

Free, C., Phillips, G., Watson, L., Galli, L., Felix, L., Edwards, P., Patel, V., and Haines, A. 2013. The effectiveness of mobile-health technologies to improve healthcare service delivery processes: A systematic review and meta-analysis. PLoS Med. 10: 1. doi: 10.1371/ journal.pmed.1001363

Galbraith, J. 2004. Active viewing: An oxymoron in video-based instruction? Understanding the nature of self-regulation behavior of learners using variable speed playback in digital video-based instruction. Proceedings of the 2004 Washington Interactive Technologies Conference (SALT), Arlington, VA.

Government of Canada. 2018. For health professionals: Lyme disease. [Online] Available at: https://www.canada.ca/en/public-health/ services/diseases/lyme-disease/health-professionals-lyme-disease. html [Accessed on July 24, 2018].

Government of Ontario. 2018. Why we need to fight climate change. [Online] Available at: https://www.ontario.ca/page/why-we-needfight-climate-change [Accessed on July 24, 2018].

Hinze, A., Vanderschantz, N., Timpany, C., Cunningham, S. J., Saravani, S. J., ., and Wilkinson, C. 2017. Use of mobile apps for teaching and research. [Online] Available at: https://researchcommons.waikato. ac.nz/bitstream/handle/10289/11033/01-2017-Working\%20Paper. pdf ? sequence $=2 \&$ is Allowed $=y$ [Accessed on July 24, 2018].

Levie, W. H. and Lentz, R. 1982. Effects of text illustrations: A review of research. Educ Commun Technol. 30(4): 195-232

Marieb, E. N. and Hoehn, K. 2007. Human anatomy \& physiology. 7th edn. San Francisco, CA: Pearson Benjamin Cummings.

Mayer, R. and Gallini, J. 1990. When is an illustration worth ten thousand words?. J Educ Psychol. 82(6): 715-726

McQueen, A., Kreuter, M. W., Kalesan, B., and Alcaraz, K. I. 2011. Understanding narrative effects: The impact of breast cancer survivor stories on message processing, attitudes, and beliefs among African American women. Health Psychol. 30(6): 674-682
Ministry of Health and Long-term Care. 2016. Infectious disease protocol: Appendix A: Disease specific chapters: Chapter: Lyme disease. [Online] Available at: http://www.health.gov.on.ca/en/pro/programs/ publichealth/oph_standards/docs/lyme_disease_chapter.pdf [Accessed on July 24, 2018].

Mohammadi, K., Tavafian, S., Ghofranipoor, F., and Amin-Shokravi, F. 2012. Health education program and tuberculosis preventive behaviors. Zahedan J Res Med Sci. 14(10): 97-99

Nelder, M. P., Wijayasri, S., Russell, C. B., Johnson, K. O., MarchandAustin, A., Cronin, K., Johnson, S., Badiani, T., Patel, S. N., and Sider, D. 2018. The continued rise of Lyme disease in Ontario, Canada: 2017. Can Commun Dis Rep. 44(10): 231-236

Ogden, N. H., St-Onge, L., Barker, I. K., Brazeau, S., Bigras-Poulin, M., Charron, D. F., Francis, C. M., Heagy, A., Lindsay, L. R., Maarouf, A. 2008. Risk maps for range expansion of the Lyme disease vector, Ixodes scapularis, in Canada now and with climate change. Int J Health Geogr. 7(1): 24.. doi: 10.1186/1476-072X-7-24

Omboni, S., Caserini, M., and Coronetti, C. 2016. Telemedicine and $\mathrm{m}$-health in hypertension management: Technologies, applications and clinical evidence. High Blood Press Cardiovasc Prev. 23(3): $187-196$

Ontario Agency for Health Protection and Promotion (Public Health Ontario). 2018. Ontario Lyme disease map 2018: Estimated risk areas. Toronto, ON: Queen's Printer for Ontario.

Shepard, R. and Cooper, L. 1982. Mental images and their transformations. Cambridge, MA: MIT Press/Bradford Books.

Statista. 2018. Internet usage frequency in Canada as of January 2018. [Online] Available at: https://www.statista.com/statistics/686835/ canada-internet-usage-frequency/ [Accessed on July 24, 2018].

Statista. [2017, April]. Mobile usage in Canada. [Online] Available at: https://www.statista.com/study/43940/mobile-usage-in-canada/ [Accessed on July 24, 2018].

Statistics Canada. 2018. Table: 22-10-0011-01 household with access to the internet at home by geography. [Online] Available at: https:// www150.statcan.gc.ca/t1/tbl1/en/tv.action?pid=2210001101 [Accessed on July 24, 2018].

The University of Queensland. n.d. Pedagogical benefits. [Online] Available at: http://www.uq.edu.au/teach/video-teach-learn/ ped-benefits.html [Accessed on July 24, 2018].

Wilches, E. C., Hernandez, N., Hernandez, O. M., Perez-Velez, C. M., and Galarza, A. M. 2011. Knowledge, attitudes, practices and education regarding tuberculosis in undergraduate students of a health faculty. Am J Respir Crit Care Med. 183: A1861. 


\section{Appendix A}

This document was adapted with the permission of Public Health Ontario. Public Health Ontario assumes no responsibility for the content of any publication resulting from translation/changes/adaptation of $\mathrm{PHO}$ documents by third parties.

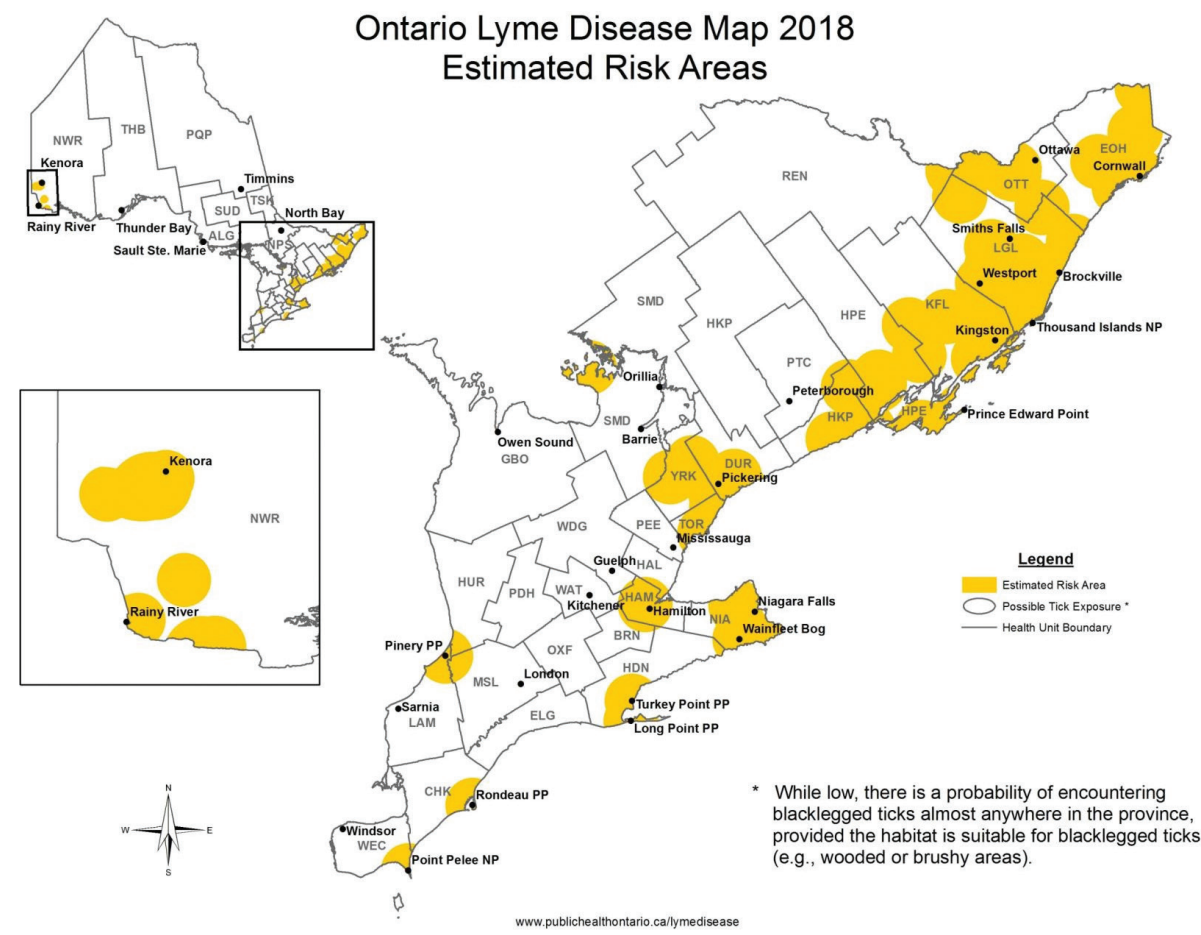

Figure A1. Estimated Lyme disease risk areas in Ontario for 2018. This information was determined by Public Health Ontario (2018). The yellow areas signify places with estimated risk while the white areas signify possible tick exposure. 


\section{Appendix B}

Images containing incorrect or inappropriate species on information pertaining to ticks and (or) Lyme disease on PHU websites.

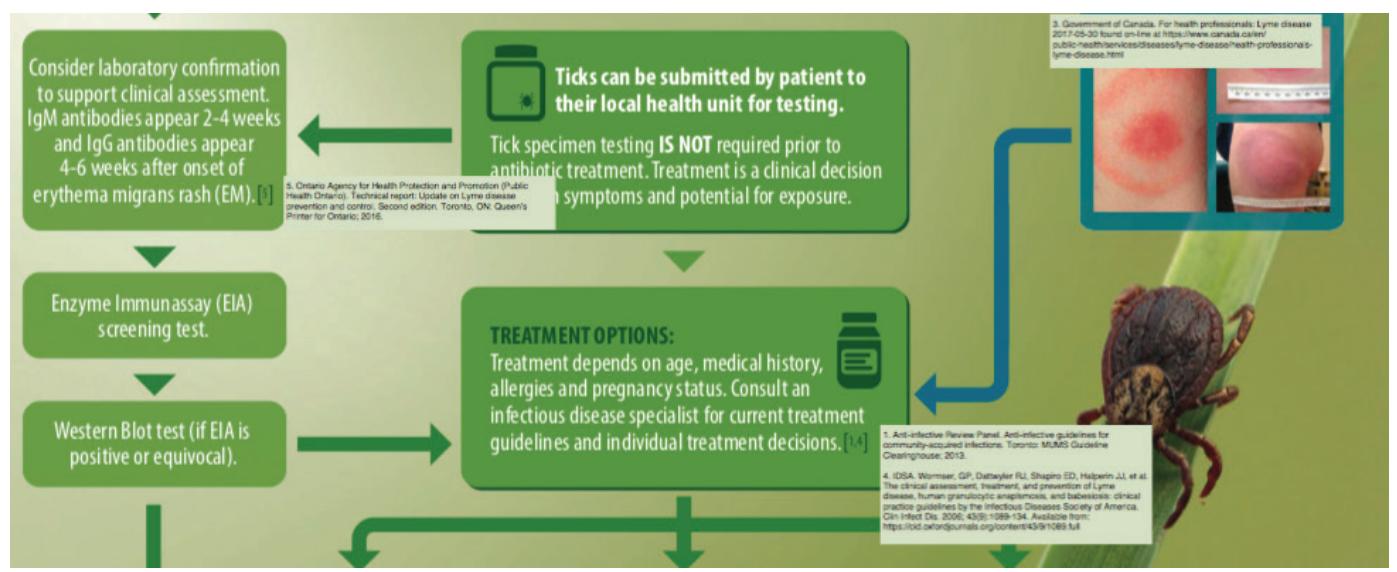

Figure B1. An image of a female American dog tick used in the background of a Lyme disease infographic for health care professionals to determine if antibiotic intervention is appropriate.

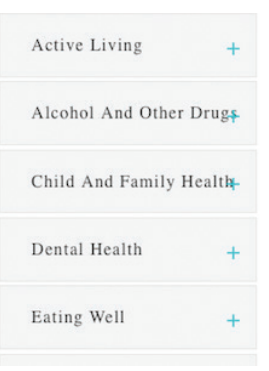

Ticks and Lyme Disease for Healthcare Professionals

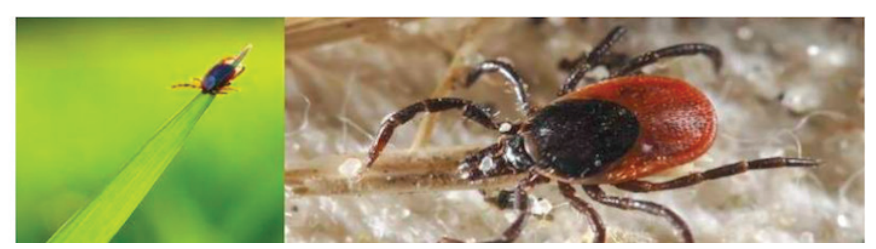

Figure B2. It appears that a picture of a female American dog tick is shown on the left-hand side of a Lyme disease website for health professionals. The crest appears to be lighter in colour while the body is dark. In contrast, the female blacklegged tick on the right has a dark crest and a bright orange body.

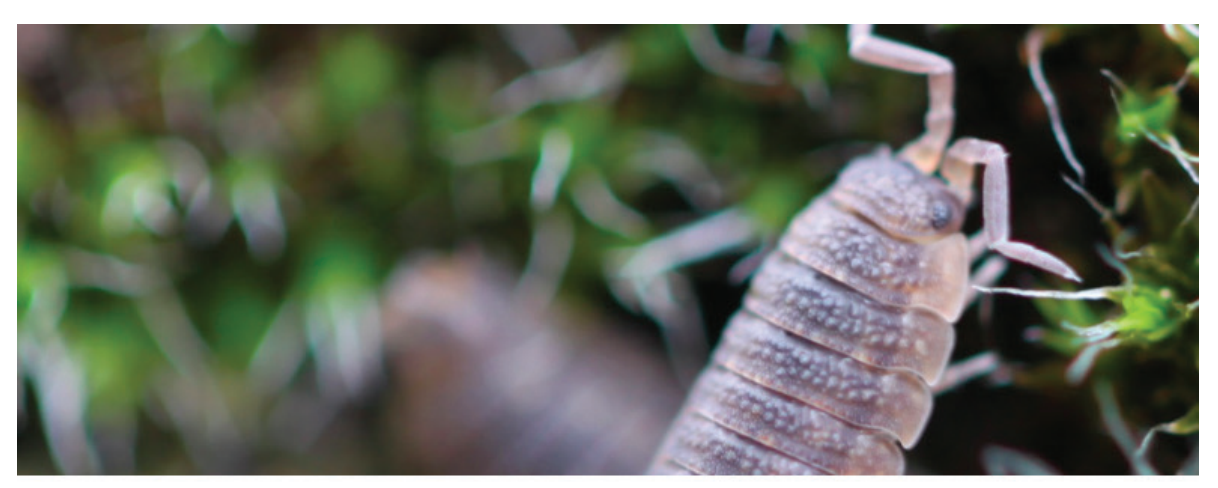

Ticks \& Lyme Disease

Ontarians are fortunate to have an abundance of wilderness that provides us with ample

Figure B3. An image of what appears to be a pill bug (Armadillidium vulgare) used as the banner for one website entitled "Ticks and Lyme disease." 